\title{
Effect of Tibial Tray Malalignment on Micromotion and Subsidence: A Preliminary Report
}

\author{
Shantanu Patil ${ }^{1}$, Nikolai Steklov ${ }^{1}$, Clifford W. Colwell $\mathrm{Jr}^{1}$, Mark Kester ${ }^{2}$ and Darryl D. D'Limaa ${ }^{1, *}$ \\ ${ }^{1}$ Shiley Center for Orthopaedic Research and Education at Scripps Clinic, La Jolla, Ca, USA \\ ${ }^{2}$ Stryker Orthopaedics, Mahwah, New Jersey, USA
}

\begin{abstract}
Malalignment of the tibial tray in total knee arthroplasty has been linked to several complications including tibial tray subsidence, leading to revision surgery. However, quantitative biomechanical evidence to directly support the mechanism of failure is not available. We developed a model to study tibial tray micromotion and subsidence in vitro under multiaxial physiological loading conditions for up to 100,000 cycles. In Phase I, we tested four cadaver knees and two surrogate bone models to determine whether the surrogate models could reproduce the fatigue damage induced by cyclic loading. In Phase II, we tested six cadaver knees in a pairwise manner under conditions representing either neutral or varus malalignment.

The surrogate bone models did not reproduce the progressive damage that was seen in human cadaver specimens. The altered loading conditions used to represent varus tray alignment increased the cyclic strain at the start of the fatigue loading and increased the cyclic strain at the end of the fatigue loading as well as the subsidence of the tray. The increase in final cyclic strain was greater in the varus condition indicating reduction in stiffness due to bone damage. This in vitro testing represents the clinical reports of early tray migration that lead to eventual aseptic loosening. This study provides biomechanical evidence supporting the hypothesis that a varus tray alignment could increase the risk of failure.
\end{abstract}

Keywords: Malalignment, micromotion, subsidence, tibial alignment, total knee arthroplasty.

\section{INTRODUCTION}

Aligning the tibial tray is typically considered a critical step in total knee arthroplasty (TKA). A number of studies have reported on the accuracy of surgical instrumentation (intramedullary and extramedullary) and surgical navigation systems [1-3]. It is generally accepted that the tibial cut should be as close to $90^{\circ}$ as possible to the long axis of the tibia in the frontal plane. Malalignment (especially in varus) has been linked to soft-tissue imbalance, increased polyethylene wear, and tibial tray subsidence leading to revision surgery [4-7]. However, not all clinical outcome studies have found a statistical correlation between tibial varus and revision surgery [8].

The link between varus malalignment and implant failure has been attributed to the increased medial compartmental loading and the generation of shear stress. However, quantitative biomechanical evidence to directly support this mechanism is incomplete. There have been a few reports of tray micromotion and subsidence under cyclic loading in human cadaver tibiae. Factors that have been shown to significantly affect tray subsidence include the type of loading, the density of cancellous bone, the presence of a cement interface, the length of the tibial stem, and the

*Address correspondence to this author at the 11025 North Torrey Pines Road, Suite 200, La Jolla, CA 92037, USA; Tel: 858-332-0166;

Fax: 858-332-0669; Email: ddlima@ scripps.edu presence of screw fixation [9-13]. However, the effect of tibial tray alignment has not been fully studied. None of these studies replicated the complex multiaxial loads that are generated during walking, almost all these tests were only carried out to a few thousand cycles and the progressive bone damage, as indicated by change in stiffness of bone near the implant-bone interface, was not clearly documented.

Surrogate bone models have been used to simulate the mechanical behavior of human bone [10]. A cementless tray when tested under cyclic loading (1000 $\mathrm{N}$ axial compression and $250 \mathrm{~N}$ horizontal shear) subsided 400 to $800 \mu \mathrm{m}$ in a polyurethane surrogate bone with orthotropic material properties [14]. In cemented trays, subsidence was lower than in the previous study, around 20 to $25 \mu \mathrm{m}$ [15]. While these surrogate bone models seem to reproduce the strength and elastic modulus of human bone, the behavior of these surrogate bone models in fatigue has not been fully validated [16].

The objective of this study was to develop a model to study tibial tray micromotion and subsidence in vitro under physiological loading conditions. We then used the model to analyze the effect of altered loading to represent tibial tray malalignment.

\section{METHODS}

\section{Study Design}

This study was conducted in two phases. In Phase I, two surrogate bone models and four human cadaver knees were 
Table 1. Donor Information of Specimens Used

\begin{tabular}{|c|c|c|c|c|c|}
\hline ID & Study Phase & Knees Tested & $\begin{array}{c}\text { Age } \\
\text { (Years) }\end{array}$ & Gender & $\begin{array}{c}\text { Weight } \\
(\mathbf{K g})\end{array}$ \\
\hline MM1 & I & 1 & 72 & Female & 69 \\
\hline MM2 & I & 1 & 71 & Male & 79 \\
\hline MM3 & I & 1 & 63 & Male & 57 \\
\hline MM4 & I & 1 & 83 & Female & 62 \\
\hline MM5 & II & 2 & 60 & Female & 68 \\
\hline MM6 & II & 2 & 52 & Male & 64 \\
\hline MM7 & II & 2 & 52 & Female & 59 \\
\hline
\end{tabular}

tested to determine whether the surrogate bone model could accurately reproduce the fatigue behavior of human cadaver bone. In Phase II, a total of six paired human cadaver knees were tested: left-sided specimens $(n=3)$ were tested at a medial to lateral load distribution of 55:45 to represent neutral alignment, while right-sided specimens $(n=3)$ were tested in 75:25 medial to lateral load distribution to represent varus alignment of $5^{\circ}$. Demographic data regarding cadaver specimens are provided in Table $\mathbf{1}$.

\section{Surrogate Bone Models}

Two surrogate bone models from Pacific Research Laboratories (Vashon, WA) were tested: 1) Cellular Rigid Polyurethane Foam with density $=0.20 \mathrm{~g} / \mathrm{cc}$, strength $=3.9$ $\mathrm{MPa}$, and elastic modulus $=137 \mathrm{MPa}$ (to simulate cancellous bone); 2) Fourth Generation Composite Tibia with simulated cortical bone (short fiber-filled epoxy with density $=1.64$ $\mathrm{g} / \mathrm{cc}$, strength $=157 \mathrm{MPa}$ and elastic modulus $=16,700 \mathrm{MPa}$ ) and simulated cancellous bone (rigid polyurethane bone with density $=0.32 \mathrm{~g} / \mathrm{cc}$, strength $=5.4 \mathrm{MPa}$, modulus $=137$ $\mathrm{MPa})$

\section{Study Design}

The qCT scans of the cadaver specimens were obtained at $0.65 \mathrm{~mm}$ slice intervals. $\mathrm{A} \mathrm{K}_{2} \mathrm{HPO}_{4}$ calibration phantom (Image Analysis Inc, Columbia, KY) was used to compute local bone density. The qCT scans were segmented using MIMICS (Materialise, Leuven, Belgium) and analyzed to assess implant size. During preparation and testing, the specimens were soaked in proteinase inhibitors [17] to inhibit degradation of material properties for the duration of the testing (approximately five days).

\section{Micromotion Sensors}

Cruciate-retaining tibial trays (Triathlon, Stryker Orthopaedics, Mahwah, NJ) were modified to enable mounting of displacement sensors shown in Fig. (1A). Five displacement sensors (MG-DVRT-3 MicroStrain, Williston, VT) with a resolution of $1.5 \mu \mathrm{m}$ and an accuracy of $3 \mu \mathrm{m}$ were rigidly attached to the tibial tray using custom aluminum holders. Malleable craniomaxillofacial plates (Leibinger Orthognathic Maxillofacial Kit, Stryker Instruments, Kalamazoo, MI) were fixed to the tibia using $1.7 \mathrm{~mm}$ self-tapping screws to serve as reference positions on the bone for the micromotion sensors. Three sensors were oriented vertically to measure superoinferior micromotion in lateral, anterior, and medial positions of the tibial tray. Two more sensors were oriented horizontally to measure anteroposterior micromotion in lateral and medial positions on the tibial tray, Fig. (1).

\section{Tray Implantation}

All tibial tray implantations were performed by a senior surgeon using manufacturer-provided surgical instrumentation. A surgical navigation system (Stryker Navigation, Stryker, Kalamazoo, MI) was used to register the tibial plateau by digitizing point clouds on the articular surface. The mechanical axis of the tibia was recorded by digitizing the intercondylar eminence and the medial and lateral malleoli. The tibial plateau was cut at $0^{\circ}$ posterior slope and perpendicular to the mechanical axis of the tibia. After templating for size, the bone was prepared for the tibial tray. The tibial tray was cemented using surgical bone cement (Simplex P, Stryker Orthopedics). A navigation tracker was mounted on the adapter used to insert the tray to monitor the alignment of the tray relative to the tibial shaft axis.

\section{Multiaxial Testing}

The implanted tibial specimens were cemented into custom fixtures for mounting on a single-station multiaxial dual force- and displacement-controlled knee simulator, Fig. (1), Force 5 (AMTI, Watertown, MA). Appropriately sized $10-\mathrm{mm}$ thick cruciate-retaining polyethylene components were inserted into the tibial trays and were articulated with cruciate-retaining femoral components. Flexion, anteroposterior translation, and axial rotation were displacement controlled. Axial load was force controlled. The tibial tray was free to translate in the mediolateral direction and free to rotate about the anteroposterior axis (in varus-valgus). A medial to lateral load distribution of 55:45 was selected to represent neutral alignment and a distribution of 75:25 was selected to represent tray alignment of $5^{\circ}$ varus. The load distribution for the neutral alignment was obtained from in vivo measured tibial force distribution during walking [18]. We measured component alignment and the axis of the lower limb in a cohort of patients that were CT scanned after knee arthroplasty $[19,20]$. The average shift in the mechanical axis of the lower limb relative to the center of the knee was $1.9 \mathrm{~mm}$ per degree of tibial component varus. This corresponded to approximately 5\% shift per degree varus relative to the mediolateral distance between the centers of the femorotibial contact areas for the tray design used in this study. ISO-recommended input waveforms for displacement controlled wear simulation [21] were used in 


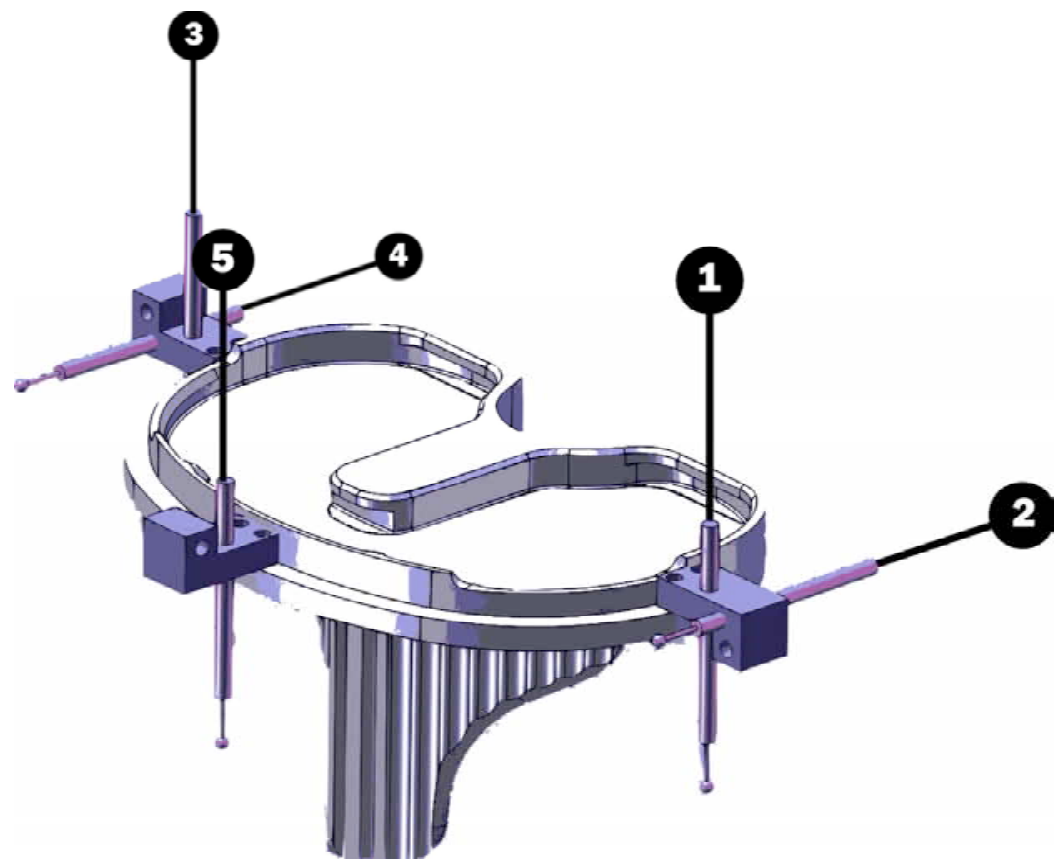

(A)

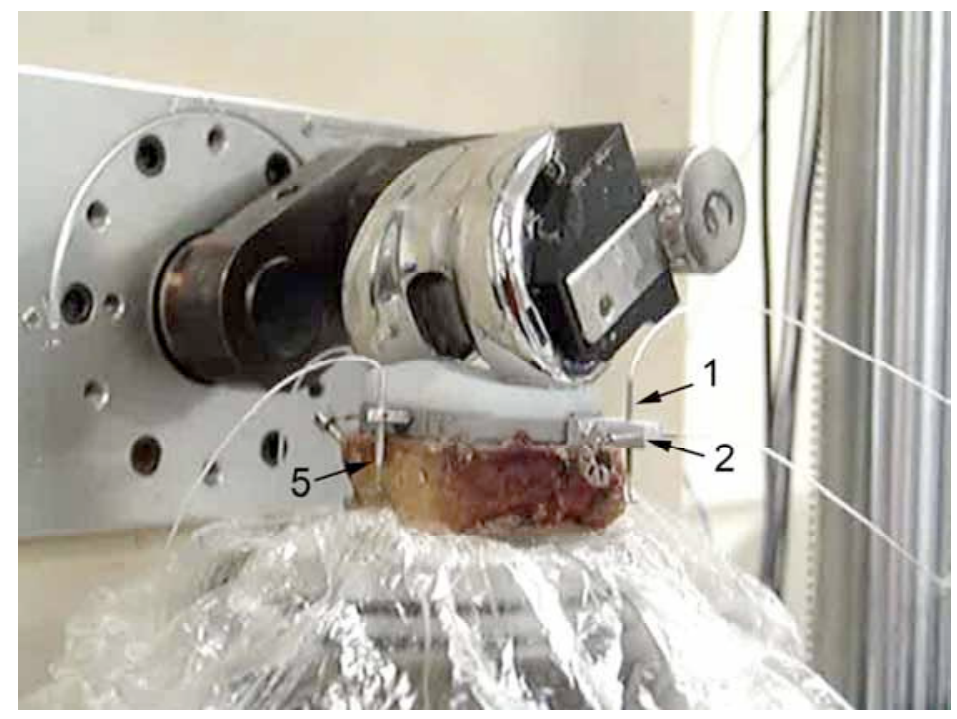

(B)

Fig. (1). A: Diagram of tibial tray mounted with micromotion sensors. Micromotion in the superoinferior direction was measured laterally (1), medially (3), and anteriorly (5). Micromotion in the anteroposterior direction was measured laterally (2) and medially (4). B: Photograph of tibial tray cemented in a cadaver tibia and mounted on multiaxial testing machine (Force 5, AMTI). Arrows point to the lateral (1) and (2) and the anterior (5) sensors corresponding to the positions in Fig. (1).

Phase I. The mediolateral distribution of load was verified using contact pressure sensors in each compartment (TekScan Inc., Boston, MA). All specimens in Phase I (surrogate and cadaver) were tested under a mediolateral load distribution of 75:25. In Phase II, the axial load was scaled to peak at 3 times the body weight of the donor (obtained as the time of death). This value was based on knee forces measured in vivo in patients implanted with electronic tibial trays $[22,23]$. The point of application of axial load was offset medially to generate a mediolateral distribution of forces of either 55:45 (left-sided tibiae) or 75:25 (right-sided tibiae). The specimens were monitored hourly for visible evidence of failure. At the end of 100,000 cycles, the test was stopped and an anteroposterior radiograph of the specimen was obtained. The amplitude of each sensor was recorded as the cyclic elastic strain. Sensor displacement was normalized to initial sensor length and expressed as strain. Subsidence was recorded as the permanent vertical displacement of the tibial tray calculated from the residual displacements in the superoinferior sensors at the medial, lateral, and anterior edge of the tray.

\section{RESULTS}

\section{Phase I}

The objective of Phase I was to determine whether the surrogate bone model could accurately reproduce the fatigue behavior of human cadaver bone. The results of testing two 
Table 2. Phase I: Comparison Between Surrogate Bone and Cadaver Bone

\begin{tabular}{|c|c|c|c|c|c|c|}
\hline $\begin{array}{l}\text { Specimen } \\
\text { ID }\end{array}$ & Specimen Type & $\begin{array}{c}\text { ML } \\
\text { Alignment }\end{array}$ & $\begin{array}{l}\text { Cycles } \\
\text { Survived }\end{array}$ & Subsidence $(\boldsymbol{\mu})$ & $\begin{array}{c}\text { Initial Cycle } \\
\text { Amplitude }(\boldsymbol{\mu})\end{array}$ & $\begin{array}{c}\text { Final cycle } \\
\text { Amplitude }(\mu)\end{array}$ \\
\hline SB1 & Cellular Rigid Polyurethane Foam & $75: 25$ & $>100,000$ & -5 & 10 & 8 \\
\hline SB2 & 4th Generation Tibia & $75: 25$ & $>100,000$ & -23 & 3 & 3 \\
\hline MM1 & Human Cadaver Bone & $75: 25$ & 26,000 & -33 & 4 & 5 \\
\hline MM2 & Human Cadaver Bone & $75: 25$ & $>100,000$ & -15 & 5 & 13 \\
\hline MM3 & Human Cadaver Bone & $75: 25$ & 6,000 & $>500$ & 40 & $*$ \\
\hline MM4 & Human Cadaver Bone & $75: 25$ & 52,000 & -250 & 33 & 90 \\
\hline
\end{tabular}

* Cadaver specimen MM3 failed catastrophically and the sensors were damaged so final micromotion was not recorded

surrogate bone models and four human cadaver knees were compared under a mediolateral load distribution representing varus malalignment for up to 100,000 cycles. Subsidence and cyclic elastic strain (amplitude of displacement per cycle) are reported in Table 2 . Both types of surrogate bone specimens survived 100,000 cycles with minimal subsidence and final cyclic elastic strain was similar to initial cyclic elastic strain indicating no significant damage. On the other hand, there was more variability in the results among the cadaver specimens (Table 2). Only one specimen survived the entire 100,000 cycle of testing. In the three specimens that failed, the trays all subsided to a greater extent than in the surrogate bone models. Cyclic elastic strain was also variable among these specimens. Note that specimen MM3 failed catastrophically with severe subsidence and damaged the micromotion sensors. Therefore, there was no record of the total subsidence or the final amplitude: the subsidence was greater than the working range of the sensors (i.e., greater than $500 \mu \mathrm{m})$.

To determine the factors contributing to the variability among specimens, we analyzed the pre-test CT scans and donor body weights at time of death. The body weights of two donors (MM3 \& MM4 in Table 1) that failed were substantially below the average for TKA patients. The peak axial load $(2400 \mathrm{~N})$ recommended by the ISO for knee wear simulation [21] therefore corresponded to greater than 4 times body weight for these specimens. The averaged bone density of the proximal tibia of these two specimens was approximately $10 \%$ lower than that of the specimen that survived (MM2).

The surrogate bone models did not sustain measurable material damage as reflected by an increase in cyclic elastic strain. We therefore selected human cadaver specimens for Phase II and chose a paired-study design to reduce specimen variability.

\section{Phase II}

All tibial specimens regardless of load distribution survived the 100,000 cycles without significant structural damage. Most of the displacement was recorded in the sensors measuring vertical displacement at the media, lateral, and anterior edge of the implant. Very little displacement was measured in the sensors measuring anteroposterior displacement. For comparison between specimens, sensor displacement was normalized to initial sensor length and expressed as strain as seen in Figs. (2 and 3 ).
The cyclic strain results are depicted in Fig. (2). In general, changing the mediolateral load distribution from 55:45 (neutral) to 75:25 (varus) increased the single cycle strain at the start of the experiment of initial strain, see Fig. $(\mathbf{2 A})$, the single cycle strain at the end of the experiment for final strain, Fig. (2B), as well as the total subsidence of the implant shown in Fig. (3).

The difference between the final strain and initial strain was assumed to be due to material damage resulting in reduced stiffness. This increase in final strain was small in the 55:45 load distribution group but was greater in the 75:25 load distribution group as shown in Fig. (2B). This increased final strain was also associated with increased net subsidence of the tray at the end of 100,000 cycles, Fig. (3).

\section{DISCUSSION}

Tray malalignment has been implicated in several complications including aseptic loosening after TKA [4-7]. The objective of this study was to develop a clinically relevant model to determine the effect of tibial tray malalignment on tray subsidence. We attempted to validate two commercially available surrogate bone models against four cadaver specimens. We then followed up with a matched-pair cadaver study to compare neutral tray alignment with varus malalignment.

We simulated the effect of varus tray malalignment by shifting the point of application of axial load more medially. In addition to a shift in the center of pressure, malalignment can also generate shear. We chose not to reproduce the shear component for technical reasons. However, no difference in the shear strain distribution at the proximal tibia was found when tibial cadaver specimens were loaded with the tibial tray parallel to the ground or at $5^{\circ}$ varus and with the femoral component in 5 or $7^{\circ}$ valgus [24]. We have previously reported on shifting the point of application of axial load to simulate the effect of tibial tray malalignment in varus [20]. More recently, another report also shifted the axial loading medially to simulate varus malalignment to study dynamic shear strain in the proximal tibia [25]. During the first phase of testing, there was marked variability among specimens in subsidence, cyclic elastic strain, and number of cycles survived (Table 2). In Phase II, we therefore decided to modify the peak load to reflect 3 times the donor's body weight. We also chose a paired-study design to reduce variability between specimens due to differences in bone density. 


\section{Average Initial Cyclic Elastic Strain}

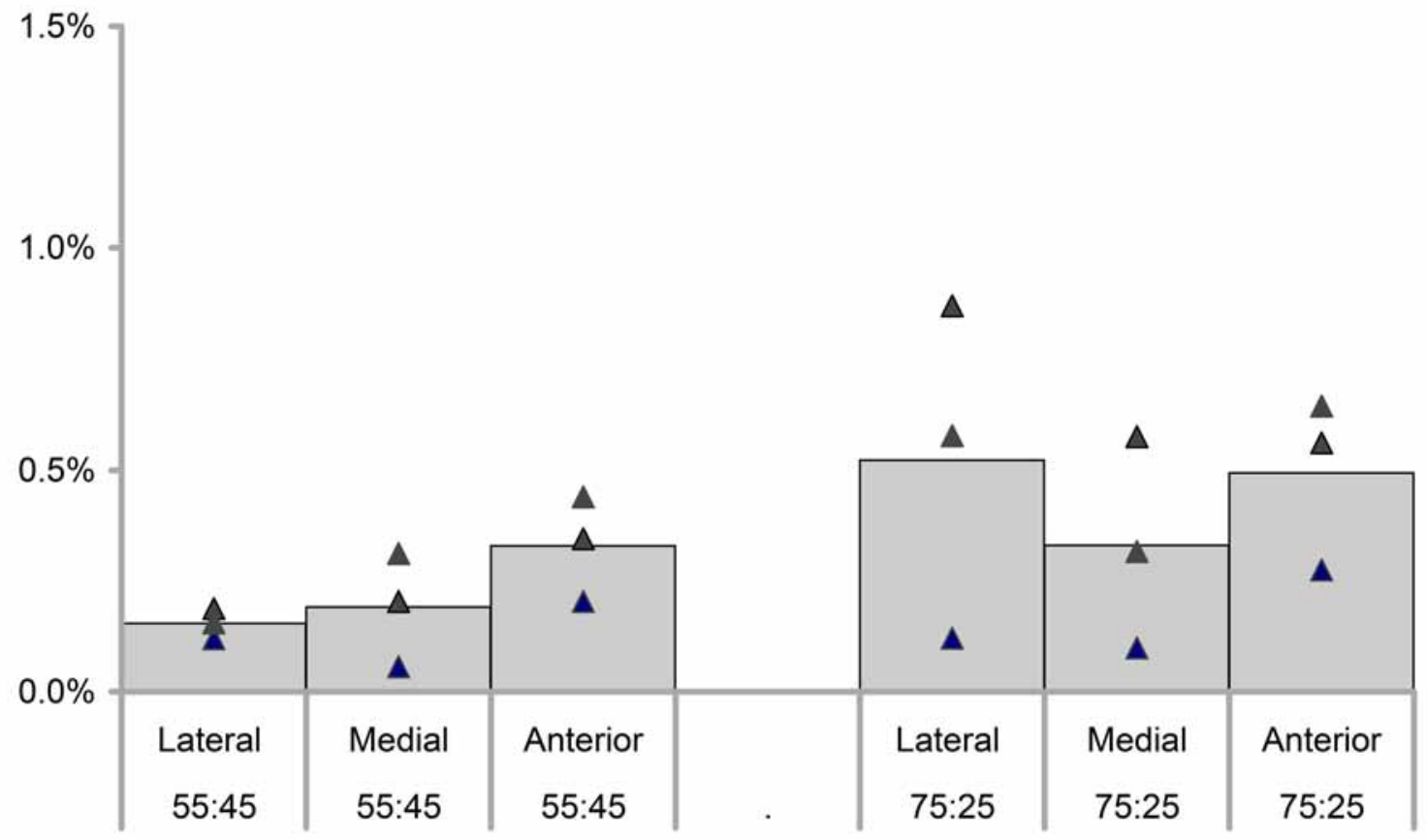

(A)

\section{Average Final Cyclic Elastic Strain}

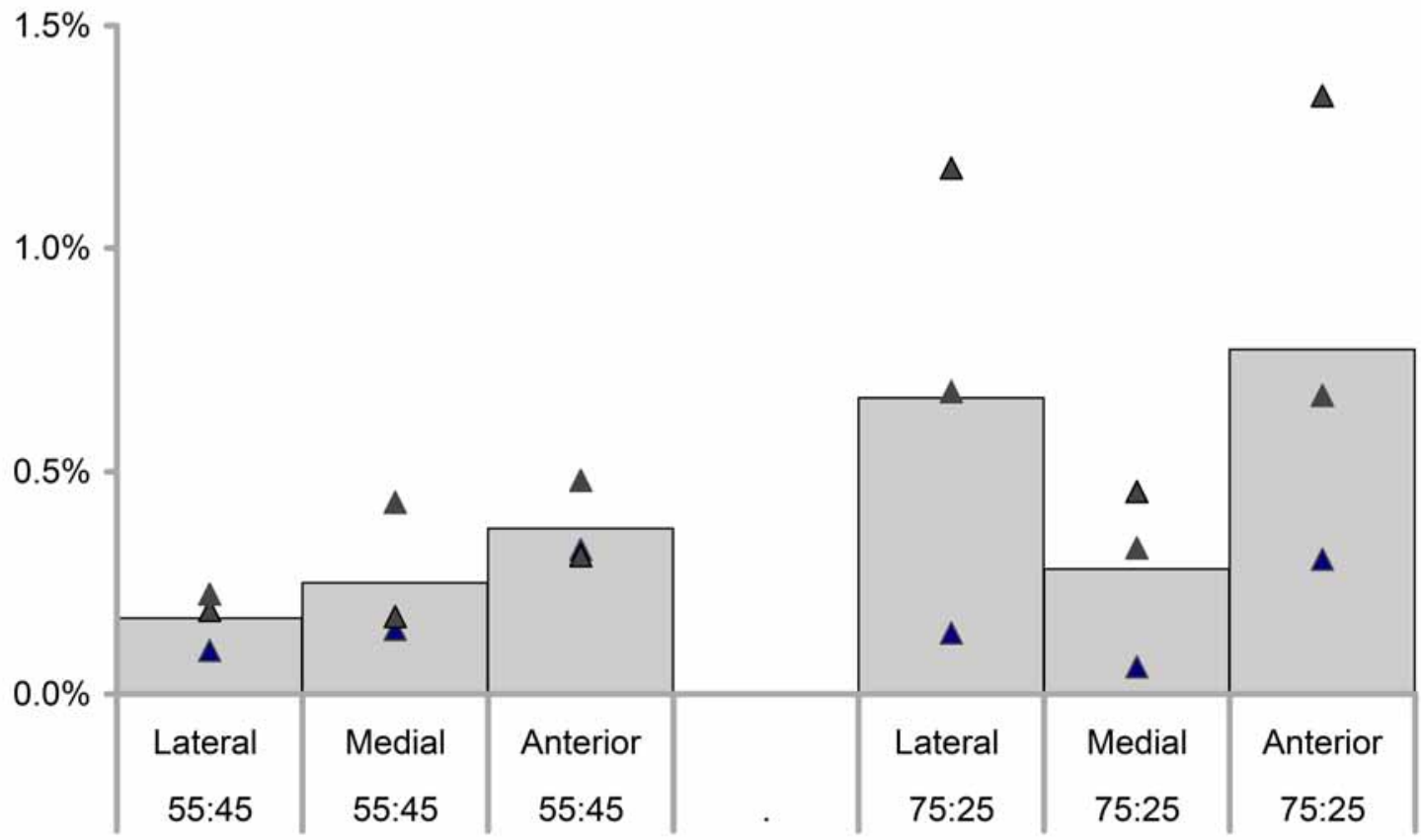

(B)

Fig. (2). The cyclic superoinferior elastic strain was measured at the medial, lateral, and anterior edge of the tray. A: The average initial elastic strain was higher for the 75:25 loading condition compared to the 55:45 loading condition. B: The average final elastic strain (at the end of 100,000 cycles) was also higher for the 75:25 condition. The elastic strains changed little over the 100,000 cycles for the 55:45 loading condition. For the 75:25 loading condition, the final elastic strain was higher than the initial elastic strain indicating a reduction in stiffness due to damage. Columns represent averages; triangles represent individual specimen data point. 


\section{Subsidence $(\mu \mathrm{m})$}

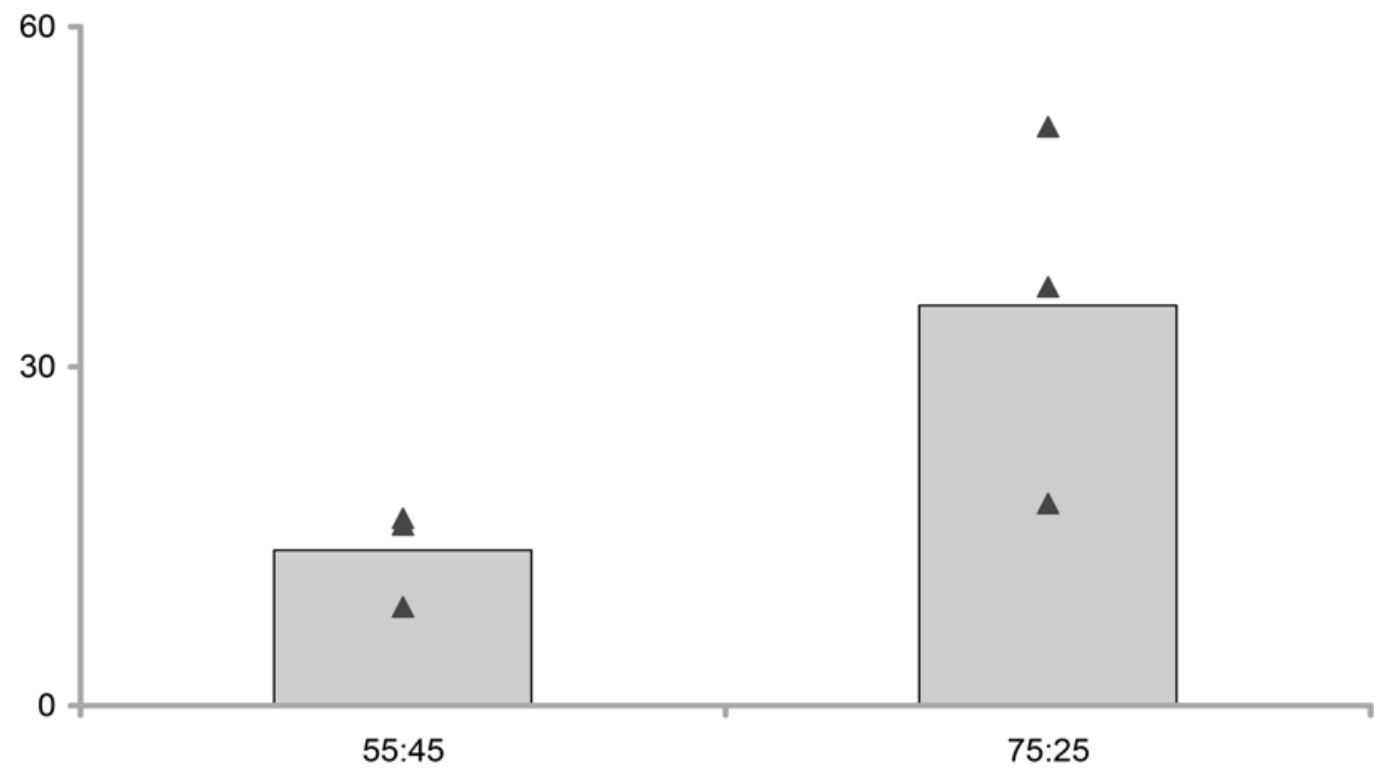

Fig. (3). Net tray subsidence for the 75:25 loading condition was almost twice that for the 55:45 condition.

In Phase I, both surrogate bone models survived the 100,000-cycle fatigue test. The initial stiffness of the implanted Cellular Rigid Polyurethane Foam was comparable to two of the four cadaver specimens. However, there was negligible subsidence and no evidence of increase in cyclic elastic strain indicating damage. The FourthGeneration Tibia was a composite of simulated cancellous and cortical bone density. The initial stiffness as well as the net subsidence of this bone surrogate model was close to that of two cadaver specimens (Table 2). However, there was no evidence of material damage over the 100,000 cycles. These commercially available surrogate bone models appear to simulate proximal tibia bone properties reasonably well for single cycle loading but might not be suitable substitutes for human cadaver specimens for bone fatigue damage. For Phase II, we therefore decided to utilize human cadaver specimens.

In Phase II, none of the specimens suffered catastrophic damage (as did three of the four specimens tested in Phase 1). This result was likely due to the fact that the peak load was adjusted to donor body weight. This adjustment appears to be clinically more relevant since early continuous tray migration and subsidence is associated with late aseptic loosening rather than severe early bone damage [6]. One unexpected finding was that the amplitudes of lateral and anterior strain increased more than the medial strain amplitude with the 75:25 load distribution. This might be attributed to a tendency to lateral lift-off and the greater sensitivity of the bone-cement-implant interface to damage in tensile loading resulting in lift-off compared to compressive loading.

Substantial differences were noted in cyclic elastic strain when the load distribution was altered from 55:45 to 75:25. Initial strain, final strain, and net subsidence all increased with a 75:25 load distribution. These findings indicated that merely shifting the point of application of net axial load by a few millimeters was sufficient to overload certain areas of the proximal tibia under the tray. It is important to note that the total strain measured by the micromotion sensor includes the strains in the cobalt-chrome alloy tray, the cement mantle, and the bone that was spanned by the sensor. However, the cobalt-chrome tray was significantly stiffer (by approximately 20 -fold) than average proximal tibial cortical bone and the combined thickness of the tray and cement mantle that was included in the sensor measurement was less than $20 \%$ of the total sensor length. Therefore, the bone strain was the major component of the total measured strain.

Fatigue damage in bone is strain related [26]. The fatigue threshold for uniaxial cyclic loading of bone in compression is approximately $0.4 \%$ strain, below which little experimental fatigue damage is usually noted. The average initial strain for the 55:45 load distribution group was below this threshold, while the average initial strain for the 75:25 load distribution group was at or above this threshold. This was further supported by our finding that the final strain for the 75:25 group was relatively greater than the initial strain indicating loss of stiffness and therefore greater underlying damage. Cyclic loading of bone above the fatigue level is also associated with permanent strain, which manifests as subsidence of the tray. Again, subsidence of the tray was greater in the 75:25 load distribution group than in the 55:45 load distribution group in keeping with the other damagerelated results.

Clinically, the rate of tibial tray migration recorded by radiostereometry is initially high and then stabilizes by two years postoperatively [6, 27-29]. The subpopulation that exhibited continuous migration (beyond 1 year) had a $20 \%$ failure rate for aseptic loosening compared with a $0 \%$ failure rate for the stable migration group [6]. More importantly, the risk for continuous migration (beyond two years) was increased in patients with initial varus alignment. Although aseptic loosening is clinically manifested after several years, 
the initial events occur very early in the postoperative period and early migration can be a marker for increased risk of aseptic loosening. An in vitro model of early migration and subsidence would therefore be of high relevance in predicting longer-term failure.

One weakness of this study was the small sample size that precluded meaningful statistical analysis. This is a preliminary report and does not permit generalizations of the results. Another weakness of this study is the absence of in vivo bone response. Bone repairs and remodels in response to stress and living bone are less prone to damage than nonviable bone. The 100,000-cycle test was completed over a span of five days with much fewer rest periods than those experienced by knee arthroplasty patients. These factors combine to make this test more aggressive than the typical clinical condition. On the other hand, only walking was simulated, while it has been shown that other activities such as stair climbing, deep knee flexion activities, jogging, and recreational activities can generate greater loads at the knee [23]. In addition, there is a general tendency for progressive aging-related osteoporosis and implant-related stress shielding in the TKA population, which would weaken the underlying bone and increase the risk for damage over time.

In summary, we developed a model to study tibial tray cyclic elastic strain and subsidence in vitro. The 75:25 load distribution generated tray displacement indicative of progressive bone damage. This study provides biomechanical evidence supporting the hypothesis that a varus tray alignment could increase the risk of failure. Potential uses of this model are to identify a margin of error for tibial tray alignment, and to develop and test tray designs that may be forgiving of malalignment.

\section{LIST OF ABBREVIATIONS}

$\begin{array}{lll}\mathrm{TKA} & = & \text { total knee arthroplasty } \\ \mathrm{qCT} & = & \text { quantitative computed tomography }\end{array}$

\section{CONFLICT OF INTEREST}

Research funding for this project was provided by Stryker Orthopaedics.

Mark Kester, $\mathrm{PhD}$, is an employee of Stryker Orthopaedics.

\section{ACKNOWLEDGEMENT}

Research funding for this project was provided by Stryker Orthopaedics.

\section{REFERENCES}

Patil S, D'Lima DD, Fait JM, Colwell CW, Jr. Improving tibial component coronal alignment during total knee arthroplasty with use of a tibial planing device. J Bone Joint Surg Am 2007; 89: 3817.

[2] Reed MR, Bliss W, Sher JL, et al., Extramedullary or intramedullary tibial alignment guides: a randomised, prospective trial of radiological alignment. J Bone Joint Surg Br 2002; 84: 85860.

[3] Teter KE, Bregman D, Colwell CW Jr. Accuracy of intramedullary versus extramedullary tibial alignment cutting systems in total knee arthroplasty. Clin Orthop Relat Res 1995; 321: 106-10.
[4] Matsuda S, Miura H, Nagamine R, et al., Changes in knee alignment after total knee arthroplasty. J Arthroplasty 1999; 14: 566-70.

[5] Ritter MA, Faris PM, Keating EM, Meding JB. Postoperative alignment of total knee replacement. Its effect on survival. Clin Orthop Relat Res 1994; 299: 153-6.

[6] Ryd L, Albrektsson BE, Carlsson L, et al. Roentgen stereophotogrammetric analysis as a predictor of mechanical loosening of knee prostheses. J Bone Joint Surg Br 1995; 77: 377 83.

[7] Windsor RE, Scuderi GR, Moran MC, Insall JN. Mechanisms of failure of the femoral and tibial components in total knee arthroplasty. Clin Orthop Relat Res 1989; 248: 15-9.

[8] Parratte S, Trousdate RT, Berry DJ, Pagnano MW. Reproducing the mechanical axis did not improve the 15-year survival of 398 modern total knee arthroplasty. Arthroplasty 2008; 23: 316.

[9] Lee TQ, Barnett SL, Kim WC. Effects of screw types in cementless fixation of tibial tray implants: stability and strength assessment. Clin Biomech (Bristol, Avon) 1999; 14: 258-64.

[10] Luring C, Perlick L, Trepte C, et al., Micromotion in cemented rotating platform total knee arthroplasty: cemented tibial stem versus hybrid fixation. Arch Orthop Trauma Surg 2006; 126: 45-8.

[11] Perez-Blanca A, Prado M, Ezquerro F, Montanez E, Espejo A. Addition of a short central extension to surface cemented tibial trays in primary TKA: an in vitro study of the effect on initial fixation stability and its relationship to supporting bone density. Clin Biomech (Bristol, Avon) 2008; 23: 483-92.

[12] Stern SH, Wills RD, Gilbert JL. The effect of tibial stem design on component micromotion in knee arthroplasty. Clin Orthop Relat Res 1997; 345: 44-52.

[13] Yoshii I, Whiteside LA, Milliano MT, White SE. The effect of central stem and stem length on micromovement of the tibial tray. J Arthroplasty 1992; 7 Suppl: 433-8.

[14] Shirazi-Adl A, Patenaude O, Dammak M, Zukor D. Experimental and finite element comparison of various fixation designs in combined loads. J Biomech Eng 2001; 123: 391-5.

[15] Lee RW, Volz RG, Sheridan DC. The role of fixation and bone quality on the mechanical stability of tibial knee components. Clin Orthop Relat Res 1991; 273: 177-83.

[16] Chong AC, Miller F, Buxton M, Friis EA. Fracture toughness and fatigue crack propagation rate of short fiber reinforced epoxy composites for analogue cortical bone. J Biomech Eng 2007; 129: 487-93.

[17] Frank EH, Grodzinsky AJ, Koob TJ, Eyre DR. Streaming potentials: a sensitive index of enzymatic degradation in articular cartilage. J Orthop Res 1987; 5: 497-508.

[18] Zhao D, Banks SA, D'Lima DD, Colwell CW Jr., Fregly BJ. In vivo medial and lateral tibial loads during dynamic and high flexion activities. J Orthop Res 2007; 25: 593-602.

[19] Chauhan SK, Scott RG, Breidahl W, Beaver RJ. Computer-assisted knee arthroplasty versus a conventional jig-based technique. A randomised, prospective trial. J Bone Joint Surg Br 2004; 86: 3727.

[20] Hermida JC, Fischler A, Colwell CW Jr., D'Lima DD. The effect of oxidative aging on the wear performance of highly crosslinked polyethylene knee inserts under conditions of severe malalignment. J Orthop Res 2008; 26: 1585-90.

[21] International Standards Organization. Standard number 14243-3: Implants for surgery; Wear of total knee joint prostheses: Part 3: Loading and displacement parameters for wear-testing machine with displacement control and corresponding environment conditions for test. Geneva: Switzerland 2000.

[22] D'Lima DD, Patil S, Steklov N, Chien S, Colwell CW. In vivo knee moments and shear after total knee arthroplasty. J Biomech 2007; 40: S11-7.

[23] D'Lima DD, Steklov N, Patil S, Colwell CW Jr. The Mark Coventry Award: in vivo knee forces during recreation and exercise after knee arthroplasty. Clin Orthop Relat Res 2008; 466: 2605-11.

[24] Green GV, Berend KR, Berend ME, Glisson RR, Vail TP. The effects of varus tibial alignment on proximal tibial surface strain in total knee arthroplasty: The posteromedial hot spot. J Arthroplasty 2002; 17: 1033-9.

[25] Berend ME, Small SR, Ritter MA, Buckley CA. The effects of bone resection depth and malalignment on strain in the proximal tibia after total knee arthroplasty. J Arthroplasty 2010; 25: 314-8. 
[26] Pattin CA, Caler WE, Carter DR. Cyclic mechanical property degradation during fatigue loading of cortical bone. J Biomech 1996; 29: 69-79.

[27] Nelissen RG, Valstar ER, Rozing PM. The effect of hydroxyapatite on the micromotion of total knee prostheses. A prospective, randomized, double-blind study. J Bone Joint Surg Am 1998; 80: $1665-72$
[28] Ryd L. Micromotion in knee arthroplasty. A roentgen stereophotogrammetric analysis of tibial component fixation. Acta Orthop Scand Suppl 1986; 220: 1-80.

[29] Toksvig-Larsen S, Ryd L, Lindstrand A. Early inducible displacement of tibial components in total knee prostheses inserted with and without cement: a randomized study with roentgen stereophotogrammetric analysis. J Bone Joint Surg Am 1998; 80: 83-9.

Received: May 01, 2012

Revised: September 24, 2012

Accepted: December 30, 2012

(C) Patil et al.; Licensee Bentham Open.

This is an open access article licensed under the terms of the Creative Commons Attribution Non-Commercial License (http://creativecommons.org/licenses/by$\mathrm{nc} / 3.0 /$ ), which permits unrestricted, non-commercial use, distribution and reproduction in any medium, provided the work is properly cited. 